\title{
O performativo no jornalismo cultural: uma organização discursiva diferenciada
}

\section{RESUMO}

O texto apresenta uma reflexão sobre o discurso de jornalismo cultural do Caderno 2, do jornal O Estado de S.Paulo, na cobertura da FLIP- Feira Literária Internacional de Paraty/2008. Discute-se como se dá a organização discursiva das matérias com o objetivo de identificar o aspecto performativo do jornalismo, tanto por sua própria presença no veículo quanto pela posição ocupada pelos jornalistas da publicação no cenário da crítica cultural. Avaliadas as condições de produção, remete-se ao "contrato de comunicação" estabelecido entre o suporte e seus leitores. Parte-se de uma revisão de literatura dos conceitos fundamentais de linguagem e discurso para uma aplicação ao jornalismo cultural.

\section{PALAVRAS-CHAVE}

jornalismo cultural

performativo

FLIP

\section{ABSTRACT}

The text presents a reflection about the cultural journalism discourse of the Section 2 from the newspaper $O$ Estado de São Paulo, covering the FLIP - Paraty International Literary Festival/2008. It is debated how these news' discursive organization occurs, aiming to identify the performative aspect of journalism, not only because its presence in the newspaper, but also because of the position occupied by the publication's journalists in the cultural critique scenario. With the production conditions analyzed, the text then refers to the "Communication contract" established between the support and its readers. It starts from a literature review of the fundamental concepts of language and discourse to apply them on cultural journalism.

\section{KEY WORDS}

cultural journalism

performative

FLIP
Os suplementos, revistas e outros veículos especializados em cultura têm sido estudados sob uma dupla perspectiva: ou são produtos que conservam as características fundamentais que deram origem a esta especificidade do jornalismo, marcado pelo recorte na temática cultural, para o qual confluem os diferentes gêneros do jornalismo, origem vinculada à constituição de uma esfera política de discussão, tal como aponta Habermas (1984); ou são manifestações que retiram legitimidade de sua história, mas na prática estão envolvidas com determinações de natureza mercantil e publicitária. Na primeira hipótese, o jornalismo cultural conservaria em suas características fundamentais uma dinâmica estabelecida a partir de demandas estético-conceituais que dizem respeito ao ordenamento institucional e às formulações acadêmicas produzidas na sociedade, uma visão idealizada do jornalismo cultural. Na segunda, seus condicionamentos seriam os da cultura de massa: uma produção mercantil voltada para o simples entretenimento, desprovida daquele compromisso com a conversação crítica de seu público, uma percepção negativa e essencialmente economicista sobre sua prática.

Consideramos a polêmica discussão que envolve o papel do jornalismo cultural, especialmente nos meios de comunicação de massa e propomos, neste estudo, uma discussão deste jornalismo a partir da "fórmula do performativo", tal como conceituada por Prado (2005). Para este autor, a linguagem jornalística, mais que designar fatos de acordo com suas características específicas de representação, constitui-se em "fórmula do performativo", isto é, indicativos de uma ação concretizados naquilo que Deleuze (apud Prado, 2005) chama de "ato ilocucionário", um discurso de ação que exerce sobre o leitor as características de uma "palavra de ordem", de um ditado valorativo em torno do objeto descrito ou informado na matéria jornalística.

Este trabalho tece uma reflexão desse conceito, primeiramente a partir de referencial teórico que subsidia uma leitura diferenciada da constituição discursiva do jornalismo cultural, e depois a partir de exemplos extraídos do Caderno 2, suplemento cultural do jornal $\mathrm{O}$ Estado de S.Paulo, mais especificamente no que refere à cobertura da Festa Literária Internacional de Paraty - FLIP 2008, realizada de 02 a 06 de julho. Para tanto, foram examinadas as edições deste suplemento dos dias 28 de junho a 07 de julho de 2008, abrangendo o final de semana anterior à Feira, o período de realização deste, e o dia posterior ao seu encerramento.

Do ponto de vista metodológico, a opção que norteou a investigação foi a da análise qualitativa de conteúdo, uma vez que é na leitura e na interpretação das matérias do suplemento que reside a possibilidade de desvendar, 
com maior propriedade, essa primeira perspectiva do jornalismo cultural, isto é, a relação bipolar existente entre mercado e reflexão. Ao mesmo tempo, tendo em vista a hipótese de que se trata de produção jornalística performativa, o procedimento adotado foi o da Análise do Discurso, considerando que a leitura extrapola a busca dos significados textuais e incorpora o conhecimento das condições de produção como fundamentais na constituição dos efeitos de sentido. Por sua vez, a escolha da FLIP como temática de estudo do comportamento do veículo justifica-se porque se trata de evento carregado da dupla dimensão com que o jornalismo cultural é analisado num primeiro momento e que dinamizam a ação de uma força econômica poderosa no panorama nacional: a indústria editorial e sua de penetração junto ao público leitor do Caderno 2.

A escolha do material de pesquisa, do qual exemplos são extraídos para demonstrar aspectos teóricos, devese ao lugar que o Estadão ocupa no jornalismo cultural brasileiro, em especial pelas relações estabelecidas com a intelectualidade paulista e pelo papel aglutinador que, em épocas sucessivas, seus cadernos de cultura tiveram no quadro geral do pensamento nacional. Além disso, o jornal $\mathrm{O}$ Estado de $\mathrm{S}$. Paulo tem uma imagem pública reconhecidamente conservadora no tratamento editorial que dá às questões políticas e econômicas, fato esse que o próprio veículo capitaliza como atributo de coerência e de confiabilidade junto aos leitores, parcela dos quais busca o jornal exatamente por essas características. Seus suplementos de cultura, no entanto, apresentam uma variação substancial em relação a esses pressupostos, já que historicamente têm sido espaços plurais de manifestação de vários segmentos e correntes de pensamento da intelectualidade.

O Caderno 2 é publicado todos os dias, inclusive aos domingos, quando recebe o título de Cultura. As pautas das edições diárias do Caderno 2 não indicam uma temática fixa de agendamento, isto é, seções permanentes em cada uma das edições, exceto naturalmente aquelas que formam a estrutura básica do suplemento (notas breves, horóscopo, coluna social, programação da $t v$, palavras cruzadas, programação de filmes etc), de forma que as matérias das edições analisadas trataram alternadamente de artes plásticas, cinema e literatura, quadrinhos, teatro etc, independentemente do dia da semana em que foram publicadas.

\section{No começo, a linguagem}

No Comunicação e Linguagem são conceitos complementares e interdependentes, a comunicação não pode ser abordada apenas pelo aspecto técnico ou tecnicista e a linguagem não pode ser considerada como simples instrumento de comunicação. Parte-se do pressuposto de que toda realidade transformada em linguagem é uma forma de interpretação ou uma representação dessa realidade, portanto, é impossível uma análise de textos da comunicação com abordagem estritamente lingüística; há que se considerar as condições de produção das mensagens. Nesse sentido, a Análise do Discurso representa uma nova abordagem do estudo do texto além da linearidade, relacionando enunciado e enunciação como elementos fundamentais da produção de sentidos. A abordagem interna do texto leva-nos a reconhecer os mecanismos e as regras de engendramento do discurso e a análise externa, a reconstituição do contexto sócio-histórico, permite-nos entender a construção dos sentidos de cada abordagem: "esta distinção enunciação/ enunciado é apenas um exemplo da concepção da linguagem com o objetivo da constituição de uma teoria da linguagem como produção [...]. O sujeito e o sentido não existem, produzem-se no trabalho discursivo" (Kristeva, 1988, p.316).

\section{Toda realidade transformada em linguagem é uma forma de interpretação ou uma representação dessa realidade.}

Como ressalta Santaella (1996, p.330) “As linguagens não são inocentes nem inconseqüentes. Toda linguagem é ideológica, porque ao refletir a realidade, ela necessariamente a refrata. Há sempre, queira-se ou não, uma transfiguração, uma obliqüidade da linguagem em relação àquilo a que ela se refere". Da mesma forma, para Charaudeau (2003, p.67) o fundamento de todo discurso são as condições enunciativas, responsáveis por permitirem que certo mecanismo de comunicação social possa produzir sentido.

No caso estudado, tem-se, no contexto situacional imediato, a cobertura da FLIP - Festa Literária Internacional de Paraty pelo suplemento cultural do jornal $\mathrm{O}$ Estado de S.Paulo, Caderno 2.

No contexto institucional, há toda uma história da empresa jornalística em se sustentar como representante das elites culturais, fazendo do suplemento essa matriz ideológica editorial. Em termos do contexto sócio-cultural, há um sentimento de valorização do leitor, em contato com a literatura, confrontando com os interesses comerciais das editoras que são as grandes vedetes da festa literária.

Na concepção de Bakhtin (1997, p.333), há que se entender que o texto não pode ser tomado como simples objeto de análise, sem se considerar o dialogismo e a contextualização, ou seja, deve-se ter presente

[...] a complexa interdependência que se estabelece entre o texto (objeto de análise e de reflexão) e o contexto que o elabora e o envolve (contexto interro- 
gativo, contestatório, etc) através do qual se realiza o pensamento do sujeito que pratica ato de cognição e de juízo. [...] é impossível eliminar ou neutralizar nele (no texto) a segunda consciência, a consciência de quem toma conhecimento dele.

No contexto das mensagens dos meios, "estamos cada vez mais convictos de que o midium não é simples 'meio' de transmissão do discurso, mas que ele imprime certo aspecto a seus conteúdos e comanda os usos que dele podemos fazer" (Maingueneau, 2001, p.71). Assim, a complexidade dos fatores envolvidos na elaboração da mensagem atesta que a análise deve romper o estudo da linguagem puramente imanente, superando a leitura restrita dos textos como produtos lingüísticos fechados em si mesmos, para saltar em direção a uma investigação que apreenda o sentido de cada gênero em sua essência e totalidade.

Situamo-nos, portanto, no contexto dos estudos da subjetividade da linguagem, área que tem dentre seus representantes Austin ${ }^{1}$ e Searle ${ }^{2}$ filósofos e lingüistas que refletem sobre os diversos tipos de ações humanas que se realizam através da linguagem: os atos da fala, do discurso ou de linguagem. Entendem, assim, que toda linguagem é uma forma de ação: "O título da obra (de Austin) enuncia claramente a hipótese de partida: 'dizer' é, sem dúvida, transmitir ao outro, certas informações sobre o objeto de que se fala, mas é também 'fazer', isto é, tentar agir sobre o interlocutor e mesmo sobre o mundo circundante" (Charaudeau \& Maingueneau, 2004, p.72).

\section{0 fato de estar inserido naquele} espaço garante ao enunciado um valor inquestionável, que ultrapassa o significado da

\section{mensagem e passa a fer um valor agregado às características do próprio suporte.}

Austin (apud Koch, 1995) distingue os atos da fala em: locucionários, ilocucionários e perlocucionários. Os primeiros consistem na simples emissão dos sons, organizados de acordo com as regras da língua, enquanto os ilocucionários designam a força que se impõe a esses atos de locução (tal qual a de pergunta, asserção ou promessa, por exemplo). Já o ato perlocucionário "é aquele destinado a exercer certos efeitos sobre o interlocutor: convencê-lo, assustá-lo, agradá-lo, etc. - mesmo que esses venham ou não ser realizados" (Koch, 1995, p. 20). O que se observa, contudo, é que o ato de fala é ao tempo locucionário, ilocucionário e perlucucionário, ou seja, a classificação tem um objetivo pedagógico e teórico, mas na prática comunicacional sempre partimos de uma locução (ato locucionário), carregado de uma determinada força (ato ilocucionário), dependendo das intenções que se tem em relação às reações do outro, do interlocutor (ato perlocucionário).

A base desses estudos de Austin e de Searle está na descoberta da existência de determinados enunciados, ditos performativos "que têm a propriedade de poder, e, em certas condições, realizar o ato que eles denotam, isto é, 'fazer' qualquer coisa pelo simples fato do 'dizer'" (Charaudeau \& Maingueneau, 2004, p.72). São performativas, por exemplo, as decisões jurídicas, legais, que podem ter grande impacto sobre a sociedade de uma forma geral, instituindo realidades que passam a afetar toda a população de um país.

Ao transportarmos o performativo para o jornalismo cultural, ampliamos o conceito lingüístico para o âmbito midiático, porém conservamos sua essência: o fato de estar inserido naquele espaço garante ao enunciado um valor inquestionável, que ultrapassa o significado da mensagem e passa a ter um valor agregado às características do próprio suporte.

Conforme Verón (1985) “o discurso do suporte de um lado, e seus leitores, de outro, são as duas partes entre as quais se estabelece, como em todo contrato, um nexo, o da leitura" (tradução nossa). Ainda segundo o autor, é pelo funcionamento da enunciação que um discurso constrói certa imagem daquele que fala (do enunciador) e também daquele com quem se fala (do destinatário), além, evidentemente, da imagem do próprio veículo. As características do jornalismo cultural determinam, ainda que implicitamente, um critério para a seleção do que dizer e de como dizer, reconhecendo o leitor como um indivíduo de prestígio social, que busca, na leitura, elementos para a construção do seu conhecimento.

\section{O jornalismo cultural e sua natureza performativa}

No caso do jornalismo cultural, o fato de que a matéria seja publicada neste ou naquele suplemento, nesta ou naquela seção, neste ou naquele veículo, já atribui a ela um valor que ultrapassa seu significado semântico. Ela é o seu próprio significado e, por conta disso, duplamente performativo: é um "ato ilocucionário" em razão do capital simbólico de que o jornalista se encontra investido; mas é também "ato ilocucionário" porque está ali, naquele veículo e, nessa medida, sua localização vale pelo discurso, vale pelo peso que tem ao estar inserido naquele contexto enunciativo. Mais que a conversação dialógica (ou contra-argumentativa) da esfera pública segundo Habermas (1984), é esse o fato motivador da 
resposta do leitor ao qual se agrega a assinatura da matéria, a especialidade de seu autor e da linguagem de que se valeu para a análise que procede.

Diariamente, os suplementos culturais (as seções, as revistas especializadas em cultura) chegam às mãos de leitores que os consomem por motivações diversas: atualização intelectual, informações sobre roteiros de eventos, programações variadas, indicações de espetáculos e shows, lançamentos de livros, efemérides culturais em geral. Nos temas que estruturam esses veículos, isto é, aqueles em torno dos quais a especialidade de jornalistas ou de colaboradores é exercitada como crítica, um conjunto de indicativos determinantes para o público é construído.

Em seu trabalho, Prado (2005, p.40) refere-se ao "sujeito-leitor" que "deve responder, com um sim, na posição de sujeito humilde, ou com uma recusa, na condição de tentar inaugurar uma posição de contraponto, outra posição de sujeito, diversa daquela proposta na fala do enunciador", como elemento de amarração entre o discurso performático e a recepção. A hipótese, no entanto, com base nessa mesma linha teórico-conceitual é a de que o performativo pré-existe à matéria jornalística uma vez que está associado ao próprio veículo.

Nos limites deste trabalho, é necessário sintetizar o alcance dessas duas contribuições. Basicamente, é preciso considerar que o jornalismo cultural lida com pautas bastante heterogêneas, mas é possível identificar um terreno comum a todas elas: as matérias que dão conta do noticiário sobre eventos culturais e que oferecem ao leitor, performaticamente, indicações valorativas sobre o conteúdo desses eventos, transitam na esfera do estético-conceitual e/ou do ético-político. Ler a resenha da obra literária, a crítica do filme, o comentário sobre a encenação de um texto teatral, a análise de um fenômeno musical, não é apenas entrar em contato com dados objetivos e noticiosos desses eventos, mas andar sobre o cenário mais amplo dos conceitos, da interpretação de subtextos, de alegorias e de metáforas criadas no plano estético-expressivo ou acadêmico e que, invariavelmente, desembocam no conjunto de valores associados aos dois campos referidos: o dos jornalistas e o dos intelectuais, fato que coloca em contato dois espaços sociais que configuram atitudes, posturas, reciprocidades de demandas analíticas incorporadas ao habitus de cada um deles.

Há, portanto, uma cena cultural construída socialmente no jornalismo a partir da interveniência de múltiplos fatores - do escrutínio do mercado à inovação conceitual - mas, até onde é possível perceber, o elemento preponderante na sua constituição - ainda que não exclusivo - é a ocupação da esfera pública por dois campos sociais que se articulam em função de suas lógicas próprias e dialeticamente interativas.

\section{O Caderno 2 e a FLIP: uma leitura}

Explicitando ou não, um interesse epistemológico, é A cobertura do Caderno 2 sobre a Festa Literária Internacional de Paraty/2008 teve início ainda no mês de junho com as primeiras matérias sobre autores e eventos previstos para o período de realização do evento. Para este estudo, a atenção centrou-se no período de 28 de junho a 07 de julho, buscando verificar como se deu a cobertura do evento e quais os aspectos que determinaram maior atenção por parte desse suplemento cultural.

Dois repórteres do suplemento, já conhecidos do público leitor pelas críticas de literatura publicadas periodicamente no veículo, foram enviados a Paraty: Ubiratan Brasil e Antonio Gonçalves Filho, que assinam a maior parte das matérias sobre a cobertura do evento, no período observado, embora se contasse também com a participação de Daniel Piza, responsável pela entrevista com o escritor Richard Price; Vladimir Safatle, professor do departamento de filosofia da USP, que assina um ensaio sobre a temática da perversidade, apresentada pela obra da psicanalista Elisabeth Roudinesco; Francisco Quinteiro Pires, que assina com Ubiratan Brasil a matéria sobre o lançamento do livro de Humberto Werneck; Mattew Shirts participa desse material selecionado para estudo com uma crônica que retoma a personagem Capitu de Machado de Assis.

Embora se possa considerar que a atividade da crítica literária é um exercício de individualidade, a produção desses dois jornalistas, enviados especiais a Paraty, nas páginas do Caderno 2 tem se caracterizado por elementos de abrangência que vão além da simples leitura pessoal e subjetiva, já que invariavelmente suas matérias procuram contextualizar as obras analisadas no plano dos movimentos artísticos e de seus desdobramentos eventuais com questões situadas fora do âmbito literário. Nesse sentido, pode-se afirmar que a presença dos jornalistas na FLIP já é por si só um fato capaz de produzir uma relação que transcende o material noticioso sobre o evento: as matérias assinadas pelos profissionais funcionam como um roteiro indicador de qualidade das obras e como uma pauta de sugestões autorizadas junto aos leitores do Caderno $2^{3}$.

Levando-se em conta os fundamentos teóricos deste trabalho, que os critérios tradicionalmente usados para a aferição da produção jornalística e que lhe dão credibilidade por sua correspondência aos fatos noticiados, é um elemento secundário na produção do jornalismo cultural, uma vez que o que dá sustentação ao contrato de leitura é um mecanismo que precede o próprio conteúdo da notícia: o prestígio de que desfruta o jornalista, prestígio esse associado ao veículo que publica suas matérias. Nessa medida, a crítica ou o comentário sobre os escritores presentes em Paraty e suas obras adquire status normativo e performático porque funciona como uma chancela de tudo quanto ocorreu na Feira.

Desse período de dez dias, em apenas um deles (30 de 
junho) não se encontrou qualquer referência ao evento. Nos demais dias a cobertura não foi extensa, porém sempre esteve presente, variando de uma pequena nota a várias entrevistas em uma mesma edição, porém nunca excedendo o número de 4 páginas (é o caso da edição de sábado, dia 05 de julho, denominado dia de gala da festa). Considera-se significativa essa cobertura, haja vista a concomitância com outros eventos como o festival de inverno de Campos de Jordão, além de estréias no cinema e no teatro e outros lançamentos literários desvinculados da FLIP. Este levantamento quantitativo colabora para este estudo apenas como elemento indicial da relevância dessa feira de literatura para o suplemento cultural abordado para análise a propósito de discutir sobre seu aspecto performativo. Nesse sentido, destaca-se que o principal elemento desencadeador das matérias analisadas é o conceitual, o estético, ao qual se vinculam os traços político-ideológicos, subjacentes, muitas vezes, à própria formação do autor do texto e também de seu entrevistado, ficando como se fosse um acréscimo à informação, a relação comercial, a presença, nesse caso, das grandes editoras responsáveis pelos lançamentos (em nenhum momento as editoras são destacadas, elas aparecem sempre como uma informação secundária).

No dia 28 de junho, por exemplo, a temática em pauta é a relação, nem sempre tranqüila entre cinema e literatura e os nomes destacados são de Lucrecia Martel, com sua "forma peculiar de avaliar a humanidade" e Richard Price, o "craque dos diálogos, mesclando gírias e frases soltas". O autor tem muito cuidado mesmo ao introduzir no texto possíveis críticas à obra: falando sobre a oba de Richard Price, caracterizado pelo autor, Daniel Piza, como "um escritor cada vez mais respeitado", diz que "o livro se concentra no comportamento de policiais e suspeitos, cujas vozes conhecemos pela arte de Price, embora o efeito seja cansativo nas 455 páginas". Há de se observar que o operador argumentativo "embora" ameniza o aspecto negativo e conduz o leitor para uma avaliação positiva da obra em questão. A referência à editora vem sempre entre parênteses, juntamente com o número de páginas e o preço da obra - o simples fato de estar entre parênteses já denota que se trata de uma informação complementar, não essencial para a abordagem.

Na edição do dia 29 de junho ganha destaque a obra de Elisabeth Roudinesco, historiadora e psicanalista francesa, sobre a trajetória dos perversos, "A parte obscura de nós mesmos", lançamento da Jorge Zahar Editor. O recurso das aspas, da inserção direta da fala da autora da obra, juntamente com os verbos introdutores de opinião, como "escreve ela", "comentou ela", é bastante utilizado pelo autor, como um efeito de deixar sua posição bastante sutil, quase imperceptível para o leitor comum: (falando sobre a participação de Roudinesco em uma mesa na FLIP), Ubiratan Brasil diz que "vai pregar ainda contra a eliminação da perversão, o que representaria destruir a distinção entre o bem e mal que fundamenta a civilização".

$\mathrm{Na}$ página seguinte a essa entrevista conduzida por Ubiratan Brasil situa-se o ensaio de Vladimir Safatle. Nesse texto o posicionamento é claro e aberto - Safatle reconhece o valor de Elisabeth Roudinesco "reconhecida internacionalmente como uma das grandes historiadoras do movimento psicanalítico", autora de obras que figuram como "documentos importantes para todos aqueles que se interessam por um eixo importante do pensamento contemporâneo". Porém, “infelizmente, não é possível dizer que esse cuidado historiográfico exaustivo que lhe é característico esteja presente e seu último livro". E Safatle finaliza sua avaliação: "para aqueles que admiram os outros trabalhos de Roudinesco, só podemos esperar um retorno àquilo que ela fez de melhor".

Na edição de 2 de julho, a matéria de capa do suplemento trouxe uma entrevista com o escritor argentino Martín Kohan, autor de duas obras que falam sobre as condições de seu país no período da ditadura militar. É uma referência basicamente informativa porque o autor, que pertence à nova geração de escritores argentinos, é pouco conhecido do público brasileiro. Mas a essa referência, Ubiratan Brasil, autor da entrevista, associa elementos de qualificação das obras que atuam como suportes de recomendação à sua leitura. A entrevista que acompanha essas indicações, por sua vez, vem carregada de outras referências igualmente orientadoras do leitor da matéria, neste caso com o suporte que dá às questões apresentadas pelo repórter a própria localização da fala do autor.

Há aqui, no entanto, outro conjunto de elementos que assegura a eficácia do discurso performático: a importância da obra de Kohan está sendo destacada pelo repórter por seu vínculo com processos de natureza ético-políticos que têm marcado um momento de revisão da história recente da América Latina, especialmente naqueles países, como a Argentina e o Brasil, que foram vítimas de ditaduras militares. Trata-se de um processo que não é exclusivo da Literatura e que se estende a outras manifestações artísticas, à historiografia, ao jornalismo, ao Direito etc, e que, segundo entendemos, configuram o universo de temáticas que povoam o cotidiano do público leitor e do próprio jornalista, razão que nos leva a crer que a eficácia do discurso performático no jornalismo cultural está relacionada com a referência social de seus enunciados e que correspondem a demandas de natureza externa às da própria imprensa.

Nessa mesma edição do dia 02 de julho tem-se a matéria de Ubiratan Brasil sobre as "diversas homenagens a Machado". Brasil diz que "escritor homenageado pela FLIP, Machado de Assis será lembrado em diversas oportunidades" e dá destaque nesta matéria aos produtos editorais sobre Machado de Assis e adaptações de suas obras, com lançamento marcado por grandes 
editoras, durante a realização da festa literária. Machado só volta à pauta do Caderno 2 no dia 04 de julho, em uma pequena cobertura sobre a palestra de Roberto Schwartz, na abertura da FLIP: "a lição de tolerância no romance Dom Casmurro". Nova referência ao escritor só se encontra no dia 07 de julho, na crônica de Mattew Shirts, "Capitu no centro do universo".

O primeiro lançamento de autor brasileiro a ganhar destaque nessa cobertura aparece no dia 03 de julho. Trata-se da obra de Humberto Werneck, "O Santo Sujo - A vida de Jayme Ovalle", biografia do polêmico paraense, "músico, poeta, louco, místico, boêmio, funcionário público $[. .]$.$" . A discussão em torno da obra e do$ biografado gira em torno do paradoxo entre a extrema sensibilidade e a incapacidade de expressão clara: "ele era a inspiração em carne, osso e [...] espírito. Embora fosse impossível prever se Ovalle saberia articular uma frase até o fim [...]". Apenas mais dois escritores brasileiros ganham espaço nessa cobertura do Caderno 2 sobre a FLIP: no dia 04 de julho João Gilberto Noll, que lança pela editora Record a obra "Acenos e Afagos", caracterizada como um "exercício de linguagem", "o que o distingue na moderna literatura brasileira. No dia 05 de julho a obra de Carlos Lyra sobre a Bossa Nova ganha espaço com a discussão proposto pelo autor de não ser a Bossa Nova um "movimento", mas "antes um surto cultural da classe média carioca".

Não causa estranheza o destaque dado à presença dos escritores internacionais, haja vista que sua simples participação tem um efeito performativo, valorizando o evento, também que a esses nomes internacionais estão vinculados os expoentes da indústria editorial brasileira. Porém era de se esperar que a literatura nacional estivesse mais presente, seja pelo grande valor, por exemplo, de Machado de Assis, o escritor homenageado, seja pelos grandes nomes de escritores brasileiros conhecidos mundialmente.

Outro exemplo pode elucidar ainda mais a hipótese com a qual trabalhamos. A edição de 5 de julho do Caderno 2, entre todas as que se ocuparam da FLIP/2008, foi a que publicou maior volume de matérias sobre o evento, especialmente porque enfatizou a variedade de nomes, de palestras, de temas, de debates etc que, naquele dia, em especial, compunham a agenda da Feira. Nesse sentido, a própria manchete do suplemento sugeria a importância da data: "Na Flip, porque hoje é sábado", verso que ficou eternizado na literatura, pelo poema "O dia da criação", de Vinicius de Moraes, a quem o suplemento não faz qualquer menção, como se negociasse com o seu leitor esse conhecimento compartilhado.

Assuntos polêmicos são fontes de matérias atrativas no Caderno 2, como se o jornalista buscasse elementos para suprir uma necessidade de seu interlocutor, do seu leitor. É a imagem de que o leitor busca o inédito, o surpreendente, algo além da informação do cotidia- no que está nas páginas do noticiário informativo em geral. No dia 06 de julho a entrevista realizada por Antonio Gonçalves Filho, com o francês Pierrre Bayard, pauta-se no questionamento da leitura como "objeto de sacralização", abordado pelo autor na obra "Como falar de livros que não lemos". Igualmente polêmica é a abordagem da obra do jornalista e historiador britânico, Misha Glenny, cuja entrevista, também realizada por Antonio Gonçalves Filho, está na edição do dia 04 de julho. Glenny "escreveu um livro bombástico sobre as relações entre o crime organizado e o crescimento da pobreza nos países em desenvolvimento". O assunto parece ter sido selecionado no momento exato das conflituosas relações entre o poder oficialmente constituído e o poder paralelo do tráfico, em nosso país, em especial no Rio de Janeiro, estado onde se situa Paraty.

Na edição do dia 05 de julho, o do italiano Alessandro Baricco é apresentado pelo repórter como um autor que não situa sua história "nem no tempo nem no espaço" (no caso do livro Sem Sangue) e que trabalha com "relato de sensações [...], a realidade objetiva se transmuta na visão, na memória e na linguagem de um indivíduo" (no livro Seda). Segundo Ubiratan Brasil, "por sua forma original de narrar, Baricco conquista especialmente leitores mais jovens, o que lhe garantiu a faixa de 'escritor pós-moderno". Essa composição literária, no entanto, vem associada a temáticas sociais italianas do pós-guerra, à vendetta, o estímulo à imaginação a partir de narrativas em torno de enredos característicos das novelas de ação, universo de componentes sempre presentes na produção literária.

Esses exemplos, citados aqui como modelos de análise das dimensões discursivas do jornalismo, no entanto, não eludem o fato de que a FLIP, em todas as suas edições, tem características que extrapolam os limites do puro e desinteressado debate cultural. Na verdade, forma-se em torno do evento um mercado que transita do simbólico e do artístico para o econômico e as dimensões disso, registradas pelos próprios repórteres do Caderno 2, permitem deduzir que as relações estabelecidas na esfera pública entre os dois níveis não representam o acanhamento da crítica pela força dos interesses financeiros que se articulam em torno da Feira. Além da forte presença das Editoras, inevitavelmente citadas em todas as referências às obras comentadas pelos repórteres, a FLIP reuniu em, 2008, $20 \mathrm{mil}$ participantes, movimentando quase 37 mil ingressos, envolvendo estruturas político-administrativas locais e regionais e ampliando a presença da cidade que a abriga no cenário nacional e internacional. Forma-se em torno dela, portanto, uma crescente complexidade à qual o jornalismo cultural vem dar prestígio e reconhecimento, sem que se descaracterize por isso.

\section{Considerações finais}

Essa abordagem permite introduzir na análise do jor- 
nalismo cultural sua caracterização não só como espaço determinado dialeticamente por demandas de natureza mercantis e intelectuais, mas também como exercício midiático performativo, espaço de poder social estruturado pela linguagem. A construção do discurso jornalístico, dessa forma, pode ser vista genericamente como um campo de abrangência que ultrapassa o aspecto informativo ou construtor da realidade: ele estrutura a percepção dos leitores, orienta suas apreensões, conduz pragmaticamente a localização de sua recepção no complexo de sentidos presente em cada pauta. E se isso pode ser identificado como verdadeiro no plano geral das relações enunciador-enunciatário, estabelecidas pela imprensa, é ainda mais palpável no território do jornalismo cultural, dada a sua incontornável aproximação com o universo de valores estético-políticos presentes nas pautas das publicações do gênero.

Trata-se, como parece óbvio, de uma referência para a indústria editorial porque a realização da feira constituise em termômetro de tendências e de evidências de personalidades do mundo da literatura. Acredita-se que a realização do evento, por si só, tenha desdobramentos de natureza mercadológica e é possível que as livrarias tenham apresentado movimento que refletiu a publicidade que a FLIP e suas estrelas ganharam nas páginas dos suplementos culturais do Estadão e de outros órgãos da imprensa. Nesse contexto, as avaliações dos repórteres e a condução de entrevistas e recurso a fontes especializadas tornaram-se, para o leitor do veículo, "manuais" de localização cognitiva não só para a variedade dos acontecimentos internos à própria Feira, mas também para a aferição da qualidade dos autores e das correntes estéticas presentes em Paraty.

Os autores referidos no suplemento ganharam destaque não apenas pelo conjunto de atributos ético-políticos de suas obras, mas também porque a produção de alguns deles trabalha no âmbito da inovação estéticoconceitual, atributo que corresponde a questões aparentemente mais relacionadas com demandas internas da própria ficção literária expressos em movimentos internacionais da vanguarda artística. Pois em ambos os casos é possível perceber que o núcleo fundamental do texto jornalístico conduz o leitor para uma esfera pública não especializada da abordagem, constituindo-se também aqui o traço que o vincula à natureza performativa do jornalismo cultural ${ }_{\text {FAMECOS }}$

\section{NOTAS}

1 A obra de Austin, How to do things with words, publicada em 1962, reúne doze conferências pronunciadas em 1955 na Universidade de Harvard e é considerada a origem da teoria dos speech acts.

2 As obras de Searle, Speech Acts, publicada em 1969 e Expression and Meaning, em 1979, retomam e sistematizam a teoria iniciada por Austin.
3 Não se propõe, neste estudo, a elaborar qualquer crítica ou avaliação da atuação desses profissionais. A seleção das matérias analisadas justifica-se apenas como uma exigência da opção metodológica para o desenvolvimento da pesquisa proposta.

\section{REFERÊNCIAS}

BAKHTIN, Mikhail. Estética da criação verbal. São Paulo: Martins Fontes, 1997.

CHARAUDEAU, Patrick \& MAINGUENEAU, Dominique. Dicionário de análise do discurso. São Paulo: contexto, 2004

CHARAUDEAU, Patrick. El discurso de la información La construcción del espejo social. Barcelona: Gedisa Editorial, 2003

HABERMAS, Jürgen. Mudança estrutural da esfera pública. Rio de Janeiro: Tempo Brasileiro, 1984.

KOCH, I. V. A inter-ação pela linguagem. São Paulo: Contexto, 1995.

KRISTEVA, Julia. História da linguagem. Lisboa: Edições 70, 1988.

MAINGUENEAU, Dominique. Análise de textos de comunicação. São Paulo: Cortez, 2001.

PRADO, José Luiz Aidar. O leitor infiel diante dos mapas da mídia semanal performativa. Revistas Fronteiras. São Leopoldo: Unisinos, vol VII, p. 39-46, 2005.

SANTAELLA, Lúcia. A produção de linguagem e ideologia. São Paulo: Cortez, 1996.

VERON, Eliseo. El análisis del "Contrato de Letura" - um nuevo método para los estúdios del posicionamiento de los soportes de los media. In: Les Medias: Experiences, recherches actuelles, aplications. Paris: IREP, 1985. Disponível em: <http://www.hipersociologia.org.ar/ biblioteca/textos/>. Acesso $13 \mathrm{fev} 2007$. 